erous diet. Large quantities of kumyss were administered in this way. Their life beyond doubt, was prolonged for eight months, besides relieving them from the agonies of starvation, which is the usual end in such cases. I will cite one more important case from my record book, showing the importance of kumyss as a reconstructive.

A child two years old was suffering from a syphilitic tumor at the base of the interior of the epiglottis; the tumor involved the vault of the larynx, which necessitated a dangerous operation at that age. I intubed the child and by means of the stomach pump, fed it on kumyss for three months, until the action of the remedies employed for the treatment of this tumor, resulted in diminishing its size. The child recovered without m'ach loss of weight.

Many other similar cases thus treated with kumyss, I could cite, and I would advise you all to give this valuable food a thorough trial. I can highly recommend its use, in all branches of medicine, as well as in my special cases. For additional points connected with special application of "diet" dietetics for all voice users, I must refer to my article cited above.

In conclusion I would say, that I have substituted kumyss, made from kumyssgen (the new dry form of kumyss) in all cases where I formerly employed liquid kumyss, and find it much superior in many respects, both in regard to convenience of handling and in the results obtained. It is uniform in composition and I find most patients will take it readily, which is not the case with the liquid kumyss.

\section{LARYNGEAL TUBERCLE AND TUBERCULIN.}

Read in the Section of Laryngology and Otology, at the Forty-third annual meeting of the American Medical Association, held at

BY A. J. ERWIN, M.D., OF MANSFIRLD, OHIO.

It is not the object of this paper to enter upon a general study of the treatment of laryngeal tubercle with tuberculin, or to summarize the published experience of others, but merely to give you a brief account of a few cases from my own clinic, and to make a few inferences from the same. During the past year I examined sixty-three cases of tuberculosis of the respiratory organs, and treated twentysix of them with tuberculin. Of these twenty-six seven had disease of the larynx in addition to the lung disease, which was well-marked in each case, and in no case was there any indication of either inherited or acquired syphilis, viz, :

Case 1.-Wm. Brintenbucher, æt. 20; Londonville, Ohio. Cough began about January 1, 1891; had hæmorrhages April 15 and 16 ; fever and night-sweats daily ; decreased in weight 20 pounds; consumption hereditary on both sides of family

April 23, 1891, 4 P.M.-Pulse, 132 ; respiration, 30 ; temperature, 102 . Cough frequent, some expectoration containing bacilli, rilles and obstruction in the apex of the left lung, an ulcer on inner surface of left arytenoid cartilage, deep, and a quarter of an inch in diameter. Also a solid tubercle an eighth of an inch in diameter on the first trachial ring.

I treated him exclusively with tuberculin from April 23 . to August 15 , in all 54 injections from $1-20$ to 1 . minim each. The solid tubercle and the râles had entirely disappeared by May 20 , but the ulcer on the arytenoid did not close until about the first of August. Some thickening remained for two months later, by which time his cough and expeccoration had ceased, and he had increased twentynine pounds in weight. Up to this date there has not not been any return of th ' disease in his throat, but since April first his lungs show evidence of increasing tubercularization. He has not returned for treatment

Case 2.-Mrs. Jacob Miller, æt. 23; Mansfield, Ohio. Began to cough and have fever and night sweats in December,
1889 ; has had an occasional small hremorrhage; appetite and digestion good; no loss of weight, consumption heredtary on one side.

March 28, 1891, 3 P.M.-Pulse, 100 ; respiration, 24; temperature, 101. Râles in apices of lungs, cough frequent. Free expectoration containing bacilli, anæmic, fever and sweats daily ; tuberculous ulcer covering the inner surface of left arytenoid cartilage. She received 45 injections of tuberculin between March 28, and the following July 1 , without producing any change in either lungs or throat for better or worse. She died of lung disease eight months. later.

Case 3.-Mrs. George McMullen, æt. 25; Mansfield, Ohio. Cough and fever began December, 1890 ; has had two slight hamorrhages; has decreased 20 pounds in weight; lung. disease hereditary on both sides of family.

May 13, 1891, 4 P.M.-Pulse, 92 ; respiration, 22 ; temperature, 100. Râles throughout left lung; free expectoration. Sputum contains bacilli, cough frequent; left arytenoid a. little thickened, not ulcerated; appetite and digestion poor. Began injections of tuberculin May 14, 1891. By June 1, entire anterior surface of left arytenoid had ulcerated with increased thickening of the cartilage. Treatment continued to July 21 , in all 32 injections. When discontinued, the ary tenoid thickening had considerably diminished, the ulcer was about half the former size. Left lung unchanged. Appetite and digestion improved. The fever and sweats had ceased by the middle of June; her weight had increased 5 pounds. There was no return of fever or sweating, nor increase of the lung, or laryngeal disease until March, last, since which date there has been a gradual increase of the lung and laryngeal lesions. The treatment has not been renewed.

Case 4.-Wm. Masky, æt. 30; Mansfield, Ohio. Cough, fever and sweats began with the grip November, 1889; has lost 27 pounds in weight; lung disease hereditary on oneside of family.

May 18, 1891, 5 P.M.-Pulse, 120 ; respiration, 24 ; temperature, 101. Upper lobe of each lung obstructed; murmur very deficient; no râles; frequent cough ; no expectoration : mucous from throat contains bacilli ; anæmic and weakened. Larynx and trachia covered with miliary tubercles. I treated him with tuberculin from May 18 to July 1, without making any improvement on either throat or lungs. He died of pulmonary hæmorrhage three months later.

Case 5.-J. D. Tipton, xt. 26; Ashland, Ohio. Cough and fever began September. 1890; had frequent profuse hæmorrhages in April and May. Consumption hereditary on both sides of family.

May 25, 1891, 3 P.M.-Pulse, 128 ; respiration, 32 ; temperature 102. Obstruction and rales throughout the right lung, and in apex of left. Cough frequent, expectoration large sputum contained bacilli. No disease of larynx. Began tuberculin injections May 26, 1891, which were continued daily at first, and semi-weekly afterwards to Aug. 6, from one-tenth to one minim each. About July 4 an ulcer opened on the right ary-epiglottic fold, and one on the inner surface of the left arytenoid, with considerable thickening. Last examination, Sept. 7, showed no improvement in either throat or lungs. Died Jan. 1, 1892.

Cass 6.-Frank Stevens, æt. 27; Carey, O. Cough and fever began spring of 1890 ; had several large hæmorrhages in June, 1891; lung disease not hereditary, although two. brothers and sisters died of it.

Sept. 21, 1891, 3 P.M.-Pulse, 120 ; respiration, 24 ; temperature, 100 . Râles and obstruction throughout right lung; superior lobe of left obstructed ; miliary tuberculosis covering pharynx and larynx; free expectoration containing bacilli. Received tuberculin treatment for one month, in all 20 injections, without any improvement of throat or lungs. Died a few weeks later.

Case \%.-Mrs. A. Voeglir, æt. 28; Mansfield, Ohio. Cough, fever and night sweats began July, 1890 ; has lost 26 pounds in weight. No hæmorrhages; very weak and anæmic. Father and sisters died of consumption.

May 7, 1891, 4 P.M.-Pulse, 130 ; respiration, 30 ; temperature, 103. Obstruction and râles in apex of each lung, left arytenoid double as thick as the right, with deep ulcer covering anterior surface, from which pain extends to left ear: cough frequent, expectoration moderate; bacilli in sputum. Began treatment with tuberculin May 8, 1891. For the first month daily injections, beginning with one-tenth and reaching two minims each. By July 1 the obstruction and râles had disappeared from the lungs. September 5 , the thickening had left the arytenoid, but the ulcer did not entirely heal until about Nov. 1, leaving some deformity of 
the cartilage. She passed the winter without return of fever, sweats or expectoration, and scarcely any cough, with a good appetite and good digestion, and fifteen pounds of increase of weight. In March last, she had an attack of the grip, which developed some râles in apex of right lung, and some infiltration of the previously diseased left arytenoid and fold extending to the epiglottis and slight fever. She returned to the tuberculin treatment, having an injection of from one to two minims twice per week. After about half a dozen injections the laryngeal infiltration disappeared without ulcerating, and the rales ceased in the lung a week or two later. She has now scarcely any cough or expectoration, and no bacilli with sputum. No fever, and fair health. Since September first, 1892, some disease in apices of lungs, with cough and expectoration, which is again improving under tuberculin injections, but no return of disease of larynx.

I believe that had Mr. Brintenbucher and Mrs. McMullen returned to the tuberculin treatment when the disease reappeared they would again have been relieved as readily as was Mrs. Voeglir.

In addition to these seven cases treated, I examined five others last summer who did not take the tuberculin but continued other treatment. Every one of them have since died. The inferences that might be drawn from this limited experience are, viz. :

1. Tuberculin will cure some cases of tubercular laryngitis, and will generally stop its progress.

2 . The treatment must be continued much longer than is generally practiced to affect a cure.

3 . Should there be subsequent renewal of the disease, the treatment should be repeated without delay.

4. It is only in the earlier stage of tuberculosis that the tuberculin treatment is likely to be successful.

5. Considered in connection with my experience in the treatment of lung disease with tuberculin, laryngeal tubercle is less amenable to the tuberculin treatment than is phthisis pulmonalis.

In answer to the inquiry as to the results of the tuberculin treatment in pulmonary tubercle, I would say, that of the twenty-six cases treated, more than one-half were too far advanced to expect any benefit, and yet of the whole number treated one year ago, five are now in good health (June 1, 1892), without any sign or symptom of tuberculosis, four were greatly improved, but relapsed during the past spring; two of them have since died without renewing the treatment, the other two returned to the tuberculin and have again improved and are in fair health. Seventeen were not improved by the treatment. In no case was there any bad effect from the injections. I made in all five hundred and twenty-two injections of tuberculin without causing one abscess, or one case of laryngitis.

\section{THE PHYSIOLOGY AND PATHOLOGY OF THE TONSILS.} Read in the Section of Laryngology and Otology, at the Forty-thir
Annual Meeting of the American Medical Association, held at Detroit. Mich., June, 1892.

BY JOHN NORTH, A.M., M.D., Ph.C., F.S.Sc., Lond. PROFESSOR OF DISEASES OF THE NOSE, THROAT AND LUNGS, IN THE TOLEDO MEDICAL COLLEGE, TOLEDO, 0 .

Lennox Brown says: "Of the primary value of these glands there is considerable doubt, but it is certain that at a very early age, and in the great majority of instances, they exist only to become diseased, so much so that a very eminent physician has stated that were he to play the part of a Frankenstein and endeavor to create a man, he would omit the tonsils."
The term tonsil is applied to the collection of socalled lymphoid tissue known as the faucial tonsil. The tonsils are situated on each side of the fauces, between the anterior and posterior pillars of the soft palate. Gray says: "They are of a rounded form, and vary considerably in size in different individuals," he does not give their size. Holden says: "The tonsil consists of an aggregation of muciparous glands." No mention is made of their size. Ellis and Ford say: "This body (the tonsil) is an aggregation of ten or twenty follicular glands, like those over the root of the tongue, and it occupies the interval between the arches of the palate. Its sjze varies much. Its situation is marked by the presence of small holes in the mucous membrane, with. out any surface prominence; but when enlarged from disease it projects, diminishing thus the size of the isthmus of the fauces." Ranney says: "The tonsils are small bodies situated between the anterior and posterior pillars of the fauces upon either side." Delavan in Satterthwaite says: "The tonsil consists essentially of a reduplication, more or less extensive, of the oral mucous membrane, containing in its folds an abundance of the so-called adenoid tissue." Mackenzie says that the tonsils are generally about as large as a hazel nut, and "can be just seen when the mouth is wide open, projecting into the isthmus faucium." Sajous says: "Each tonsil is about 9 lines long and 6 lines wide, and its thickness is usually so limited in the normal condition as to render its examination very difficult." Rumboldt says: "If they are in a healthy condition they do not project within sight; if they are in sight, then they are in a more or less diseased condition."

Drs. Bosworth, Woolen and others claim thai normally there are no tonsils-that the enlargements we call tonsils are in reality abnormal conditions.

Dr. Roe says this in the main is true. Normally the collection of glands at these points are not noticeable on inspection of the throat, and therefore no tonsil appears to exist.

Every rhino-laryngologist knows that less than 50 per cent. of all the throats that he looks into have no tonsils, as we understand the word tonsil, referring to a protruding gland occupying the space between the anterior and posterior pillars. If we were to look in to the throats of a large number of people, men, women and children, we would be surprised at the small number of tonsils that we can see, and when we do find them we find them associated with chronic naso-pharyngeal troubles, and not with a healthy naso-pharynx.

Now let us inquire and examine into what we do find between the anterior and posterior pillars of the soft palate. Gray, without saying anything about their size or thickness, says: "Its inner surface presents from twelve to fifteen orifices, leading into small recesses, from which numerous follicles branch out into the substance of the gland. These follicles are lined by a continuation of the mucous membrane of the pharynx, covered with epithelium, their walls being formed by a layer of closed capsules imbedded in the submucous tissue. These capsules are analogous to those of Peyer's glands; they contain a thick grayish secretion." In another place Gray says: "Peyer's glands may be regarded as aggregations of solitary glands." He also describes solitary glands as "small round, whitish bodies, from half a line to a line in diameter, consisting of a closed saccular 